MELANA AS A COMPLICATION OF MALARIA. By Surgeon-Captain H. DEMPSTER MasON, A.M.S., Karachi.

THE following cases, which are intended to illustrate one of the less frequent and more serious complications of malaria, have all occurred here within the last two years, during which period malarial diseases have not only affected a far larger number of soldiers than at any other period during the last decade, but the disease itself has proved of a far more virulent type, as exemplified by the profound cachexia following its attacks, the protracted period of convalescence, and the large number of men invalided either to the hills or to England.

Whether melæna is merely the outcome of a severe type of malaria acting on an already debilitated subject or not, it is a curious fact that up till 1893 not a single case had been recorded in the military hospital, whereas since then there have been no fewer than 23 cases up to date. There have been no cases among the women of the garrison, and out of a population of 200,000 not a single case has occurred at the native hospital. It occurs most commonly in men in debilitated health, the subjects of repeated and often long-continued attacks of ague after exposure to chill, less commonly in men who have only had ague once or twice, and that only laating a few hours. In some it has occurred during the cold stage, when one would, from physiological reasons, naturally most expect it. In others it has occurred with no relation to the malarial attack whatever.

The onset is usually sudden, preceded for a short interval by crampy pains in the belly, accompanied by slight hæmatemesis; the latter symptoms are so uniform that, accompanied with the above-named previous history, they are almost pathognomonic.

In the minority of the cases only has there been any preliminary diarrhœa, but in the majority and severer class the first indication of impending danger has been the passage per rectum of large quantities of pure bright-coloured blood, the bowels acting in such rapid succession that in the space of a few minutes the patient has become completely blanched, with a cold clammy skin, running pulse, and every symptom of the severest form of collapse. The pain in the belly and cramps in the legs are most severe, reminding one of the algid stage of cholera.

When it occurs in sthenic patients recovery is surprisingly rapid; the man who, during an attack, has seemed actually at death's door, expresses himself the very next day as feeling perfectly well and fit for duty. This would appear to indicate that the hæmorrhage is of a salutary and safety-valve character. The term melæna is of course theoretically a misnomer. After collapse has set in the hæmorrhage usually zeases, whether treatment has been adopted or not, but in one case neither treatment nor collapse completely stayed the bleeding, which terminated fatally eight hours after the first appearance of blood. Most of the cases after the collapse stage make an uninterrupted though very tedious recovery.

The pathological condition of the whole intestinal tract of the fatal case was one of extreme acute congestion, which extended from the cesophageal end of the stomach to the cæcum in gradually increasing intensity ; the mucous membrane was thickened, opaque, of a deep purple colour, with almost black patches on the valvulæ conniventes. About 5 or 6 inches down the jejunum were a series of very small acute shallow ulcers, with thin ragged edges. Throughout the large intestine the same condition existed excepting the ulceration. The spleen and liver were both enlarged, the former weighing 22 ozs., of a dark maroon colour, soft in texture, und acutely congested.

The treatment in all cases was directed towards combating the hæmorrhage and collapse, and has proved so successfal that one marvels alike at its effects and the recuperative vitality of the British soldier.

Dr. Gardiner RobB has been appointed one of the Poorlaw Medical Ufficers of Belfast, in succession to Dr. Jamieson, whose death from typhus fever we had recently occasion to record. There were several candidates, but Dr. Robb secured a very large majority at the first ballot.

\section{MEMORAND A}

MEDICAL, SURGICAL, OBSTETRICAL, THERAPEUTICAL, PATHOLOGICAL, ETc.

ACUTE BRONCHOCELE FOLLOWING INFLUENZA. Is January, 1893, I attended a middle-aged clergyman for an ordinary attack of influenza. Three days after the temperature had fallen, he complained of pain in the throat with difficulty of breathing. I found that the temperature had again risen, and that there was an acute inflammatory enlargement of the thyroid gland. The skin was reddened but not adherent to the gland. There was much stridor and slight dyspncea. The whole mass moved freely when the patient swallowed. The enlargement appeared to be almost uniform, both lobes and the isthmus being enlarged. The swelling was treated with hot moist applications. Salicylate of soda and iodide of potassium were given internally. The swelling had gone down considerably in two or three days, but when I last saw the patient, more than eighteen months after the illness, there was still some enlargement of the isthmus. The case seems worth recording as a companion to that recorded by Dr. Russell in the British MEDICAL JOURNAL of May 4 th.

Leeds.

C. W. Smenton, M.R.C.S., L.R.C.P.

A CASE OF FATAL H EMATEMESIS FROM ULCERATION OF GALL STONE INTO THE DUODENUM. L. H., aged 52, of no occupation, had suffered from attacks of biliary colic for nine years, and on several occasions after the attacks had subsided gall stones had been found in the motions. The last attack of colic was nine months ago, and this had been exceptionally severe. An operation had been advised at this time but had been refused.

On March 24th, 1895, he had the first attack of hæmatemesis, when he vomited more than a pint of dark partially clotted blood.

I first saw him on April 8th, during the absence of his usual medical attendant, Mr. Jordison. His skin and conjunctivæ were jaundiced, and he had suffered for some time from intense irritation of the skin, but with this exception had been quite free from pain. The abdomen was flaccid and easily palpable, and no enlargement of the liver or gall bladder could be made out. The bowels were confined, the motions clay coloured, and the urine contained bile pigment. All the other organs were healthy; his appetite was fair, and he had no pain after food. The temperature was normal, the pulse 80. He had been allowed to get up for an hour or two for two days previously.

I saw him again on the morning of March 10th, when he expressed himself as feeling better than he bad done for some time. During the afternoon of that day he over-exerted himself, and at 6 P.M. I was sent for urgently on account of renewed hæmatemesis. When I arrived (a distance of two miles) he was collapsed and almost pulseless. He had vomited about a pint and a-half of semi-fluid dark blood, just as he was sitting down to tea. By mears of injections of brandy and strychnine he rallied sufficiently to allow of his removal to bed.

At 8 P.M. he again vomited half a pint of dark blood, and passed unconsciously several loose motions containing partially decomposed blood. I injected gr. $\frac{1}{4}$ of morphine, and gr. s. $^{\prime} \sigma$ of ergotinin. I ordered these to be repeated every four hours, no food to be given by the mouth, but small pieces of ice to be sucked to relieve his intense thirst, and an ice-bag to be applied to the epigastrium. He had several hours' good sleep till 6 A.M. on March 11th, when he complained of faintness and dimness of sight, and soon afterwards vomited three pints of clotted blood, one clot showing a distinct cast of the pyloric end of the stomach and the upper part of the duodenum. He was much collapsed, with a weak and intermittent pulse. I saw him at 10 A.M. with Dr. Taylor, of Chester, and Mr. Jordison, and it was decided to continue the injections of morphine and ergotinin every four hours. At about 3 P.M. he became restless, and further bæmatemesis took place at 4 and 7 P.M. ; and he died at 9 P.M. on March 